\title{
What Barriers Keep College-Aged Females from Using the Campus Recreation Center? 大學女生使用校園康樂設施的障礙
}

\author{
David BARNEY \\ Brigham Young University \\ Weston KENSINGER \\ Penn State Harrisburg \\ Bridget MILLER \\ Oklahoma State University \\ Scott JORDAN \\ Northern Michigan University
}

\begin{abstract}
Attending college offers many opportunities for students to be involved in many different activities. One activity that may be neglected is physical activity. This applies to all groups of students, in particular College-Aged Females (CAF). The purpose of this study was to investigate factors that affect CAF students from using a college exercise and wellness facility. A sample of 269 CAF (243=Caucasian \& 24 African American Female) students (AAF) were surveyed and then interviewed as a group to better learn what barriers may be keeping them from using the campus exercise and wellness facility. Generally, it was found the CAF did not use the college and wellness facility for cultural, educational and personal reasons. The results from this study can be used to better encourage and market strategies to the CAF population on college campuses.
\end{abstract}

Keywords: College-aged Females, Physical Activity, Benefits and Barriers

\section{Introduction}

A quality campus recreation center (CRC) and the activities its staff offer serve as one of the primary recruiting methods for universities in attracting prospective students (Strand, Egeberg \& Mozumdar, 2010). These centers have grown from dark, dingy weight rooms to state of the art facilities that are student friendly and encourage physical activity K. Bunker (personal communication, March 22, 2011). Furthermore, such centers now combine multiple sport and exercise facilities such as, weight training, cardio-vascular equipment, indoor and outdoor swimming pools, sport and activity classes, nutritional assessments, foods and beverages and many other amenities. These centers are typically full of users at the beginning of each semester and during the "Spring Break Crunch", or weeks leading up to spring bread, however the number of exercisers usually dwindles down to only avid exercisers for the remainder of the semester (Barney, Miller, \& Kensinger, 2010). For many of those involved in physical activity, the CRC serves as a hub for engaging in physical activity on campus. Physical activity has been defined as any bodily movement produced by skeletal muscles that results in energy expenditure (Bouchard \& Shephard, 1994, p. 77). According to American College Health Association (2010), physical activity is a leading indicator for healthy college students (Wexler, 2016). Thus, for CRC managers and 
staff, increasing center participation and improving the health of the student body is a priority (Fountaine, Liguori, Mozumdar, \& Schuna, 2011).

Unfortunately, there are those who may choose not to use a CRC and its ancillary facilities and activities. This is a concern, as there is a general lack of physical activity among young adults on college campuses (Behrens \& Dinger, 2003). When college students arrive at their institution of choice, they are faced with a multitude of options, social engagements, and activities to be involved in that may not require physical activity. Because many college students choose to participate in these other activities, physical activity is often neglected.

Reed and Phillips (2005) studied college student's proximity to an exercise facility on a college campus and found that those who lived closer to the campus facility participated at higher intensities and for longer periods of time than their peers who lived further from the facility. It was also found that freshman and sophomore student's living on campus frequented the exercise facility more often during a 7-day week than those who resided off campus. Another study investigated the relationship between exercise and physical activity and sedentary behaviors of college students (Buckworth \& Nigg, 2004). Results suggested that men were more physically active than women during the college years. However, researchers also reported that men also spent considerable amount of time in sedentary activities, such as viewing television. The researchers found that the most frequent main sedentary behaviors were watching television and videos. They termed these behaviors as recreational sedentary behaviors. Another sedentary behavior that was defined was obligatory sedentary behaviors such as studying for exams or doing homework.

DeVahl, King, and Williamson (2005) compared two different academic reward structures to determine whether varying levels of academic incentives would increase adherence to a physical activity program that would be more effective for students. They found that students in the group with the potential for a greater academic reward (better grades) achieved higher program adherence and had better health outcomes compared to participants who received a lower level of incentives (lower grades).

\section{Participation and Ethnicity}

Although many students choose to use a CRC, many do not irrespective of the incentives and efforts of the CRC management and staff. More specifically, women and ethnic minorities appear to use these facilities (Barney, Miller, \& Kensinger, 2010). Studies suggest that nationally, African American Females (AAF) have the lowest levels of physical activity for both race and gender (Banks-Wallace \& Conn, 2002). This is a concern, as 55\% of AAF are physically inactive as adults (Ainsworth, Wilcox, Thompson, Richter, \& Henderson, 2003). This lack of physical activity in the AAF community can lead to many serious health consequences, with obesity being the most prevalent and life threatening. (D'Alonzo \& Fishetti, 2008). Generally, research has shown that physical activity helps decrease risks of chronic and prevalent diseases, such as cardiovascular disease (Conroy, Cook, Manson, et. al., 2002; Pate et. al., 1995), type II diabetes, cancer, osteoporosis, depression (American College of Sports Medicine, 2006; Kahn et. al., 2002), hypertension and high cholesterol (US Department of Health \& Human Services, 1996). The ancillary impact of obesity causes AAF to have a twofold higher prevalence of type II diabetes and stroke with almost a three times greater risk of mortality (Nies, Vollman, \& Cook, 1999). Further, AAF's have a higher rate of cardiovascular disease than their Caucasian counterparts and the highest rate of hypertension between these groups (D'Alonzo \& Fishetti, 2008).

Because of the health risks among AAF's, it is important to understand why they might not choose to use a CRC or participate in its programming. D'Alonzo and Fishetti (2008) reported that Black and Hispanic college-aged women suggested that vigorous exercise was unfeminine and viewed their body type differently to Caucasian women. In addition, many Black women felt pressured to exercise to conform to "White" standards of beauty.

Barney, Miller, and Kensinger (2010) collected data on the CRC use at one collegiate institution. They found that while the percentage of students that used the facility was high, there were substantially fewer visits from AAF. Specifically, only $51 \%$ of the student body's AAF's had visited the facility during a spring semester as compared to $70 \%$ of African-American males. Results 
also indicated that AAF had the lowest center usage of all gender and race subgroups. College-aged females (CAF) participate less in physical activity than their male counterparts. Thus, the purpose of this study was to better understand the perceived benefits and barriers of CAF utilizing the CRC.

\section{Methods}

\section{Participants}

Participants were Caucasian and African-American female college students enrolled at a four-year university in the South plains of the United States $(n=269)$. Of the participants $243(90.3 \%)$ described themselves as Caucasians and 24 (8.9\%) described themselves as African-American. These numbers were consistent with the reported ethnic profile of the university. Participants' ranged from 18 to 27 years of age. Most participants reported that they were not student athletes (92.9\%) or intramural athletes (90.3\%). Two hundred and eight participants or $77.3 \%$ of the sample reported being involved in physical activity classes in high school and $74.7 \%$ reported receiving parental support to exercise while they grew up. However, when asked about their current physical activity habits in college, $80.3 \%$ of participants did not meet the American College of Sports Medicine's guideline of exercising at least five days per week (Haskell, et al., 2007)

\section{Procedures}

Convenience samples of college females were recruited from general education classes. The researchers attended the general education classes and queried for student participation. The researcher explained the survey (See Table 1), asking for volunteers to participate before they signed informed consent. Participants were assured their voluntary decision to participate or not participate in the study would not affect their grade in class or class standing. Completion of survey explanation, administration, and document return took approximately 15 minutes (Barney, Pleban, Wilkinson, \& Prusak, 2015). The researchers also solicited participation from the African American campus club. To enlist participation from the African American female population the researchers visited the weekly African American campus organization meeting to invite their participation and explained the purpose of the study. Participants were asked to volunteer, read, sign, and return the informed consent form before anonymously completing the survey. After the surveys were completed, both groups of participants were invited to discuss their perceived barriers to physical activity in a focus group setting. The focus group met at a predetermined time during the week to discuss their perceived barriers with the researchers.

\section{Instrument}

To uncover why CAF choose not to use the CRC, a mixed methods approach was utilized. First, participants completed an online survey containing questions regarding demographics, physical activity habits, preferences, physical activity history, and the Expected Outcomes and Barriers of Habitual Physical Activity (EOBHPA) survey (Steinhardt \& Dishman, 1989). The purpose of this instrument was to develop a selfreport scale for outcome-expectancy values and perceived barriers for physical activity that can be tested in various physical activity settings. The EOBHPA is a 26-item instrument, which asks participants to indicate their level of agreement or disagreement using a five point Likert scale responses regarding their perceived benefits and barriers to physical activity. High scores indicate a stronger level of agreement with the statement. The EOBHPA has shown high validity and reliability (Steinhardt \& Dishman, 1989). The instrument identified three outcome-expectancy psychometric factors (psychologic, body image, health) and three perceived barrier factors (time, effort, obstacles). Second, participants were asked to take part in two small groups. During the focus groups researchers asked the CAF participants to elaborate about the specific barriers they face to physical activity and attending the CRC. Two highly qualified exercise/wellness professors lead the focus groups in a duel moderator style. One moderator focused on having the session run smoothly while to other made sure that the participants gave responses to all the questions.

\section{Data Analysis}

A total of 269 females participated in the study. Data was analyzed using SPSS 21.0 (2012). Not all participants completed the survey in its entirety; some did not supply an answer for a specific question. In these instances, cases (participants) were excluded from analyses only if data were missing for that item. An independent t-test analysis was run to uncover differences of benefits and barriers to physical activity between Caucasian and 
AAF. Further, in an effort to assist practitioners in the field, researchers collected anecdotal evidence using a small focus group semi-structured discussion with AAFs to anecdotally identify specific barriers to physical activity. All data were tested at $\alpha \leq .05$. Field notes were taken during focus group discussions. The researchers read and re-read participant responses. Four common themes materialized (Mueller \& Skamp, 2003).

\section{Results}

Findings from the EOBHPA utilized in this study were that the top five benefits of physical activity, based on item mean scores were (1) "good health," (2) "stay in shape," (3) "make me feel better in general", (4) "maintain proper weight," and (5) "appearance" (Table 2). With respect to ethnicity, Caucasian participants perceived significantly greater benefits derived from physical activity than their AAF counterparts on Appearance $[t(1,264)=$ 2.34; $\mathrm{p}=.020]$, Psychological Effect $[\mathrm{t}(1,264)=2.16$; $\mathrm{p}=.03]$, and Body Image $[\mathrm{t}(1,265)=2.12 ; \mathrm{p}=.04]$ (Table $3)$. Internal consistency of the scales ranged from $\alpha=0.47$ -0.78 with test-retest correlations from $0.66-0.89$.

The top five barriers reported, based on item mean scores were (1) "too busy," (2) "not enough time," (3) "too tired," (4) "lacked motivation," and (5) "school" (See Table 4). Independent t-test comparisons between the two ethnicities revealed a significant difference on "school" $[\mathrm{t}(1$, 263) $=3.17 ; \mathrm{p}=.002$ ] whereby Caucasian participants perceived it to be a higher barrier to physical activity. When grouped by subset, Caucasian participants reported higher barriers for only "time" $[\mathrm{t}(1,26)=2.51$; $\mathrm{p}=.01$ and "effort" $[\mathrm{t}(1,26)=2.06 ; \mathrm{p}=.04]$ (Table 5).

\section{Focus Group Data}

The focus group (17 females) discussion with the $\mathrm{CAF}$ revealed more specific reasons as to why AAF may not engage in physical activity. Specific reasons as reported by this focus group were that (1) "within the AAF community there is a cultural ideal that women should be "thick," (2) "exercise is a "white' behavior," (3) "AAF do not define being overweight as being unhealthy", (4) "AAF are less concerned about weight gain, and have a differing ideal of what a healthy body should be", (5) the environment of the fitness facility was not welcoming to the black population, (6) many of the participants in this focus group were not informed that they did not have to pay when they came, that their student fees covered their use for the fitness facility, and (7) the fact of having to care for their hair grooming and the amount of time it takes was not something these participants wanted to have to do. One participant stated that her boyfriend liked her the way she was, not a "skinny girl." Another participant stated that her mother taught her to be proud of herself, particularly her weight. In general, AAF were not motivated to exercise by body image like many Caucasian women were. The physically active AAF women from this population reported that longevity and quality of life were what motivated them to come to the CRC rather than to lose weight. Another participant stated, "I wish the TV's in the cardio area would show the Oprah (Winfrey) show, and music that blacks liked."

\section{Discussion}

The purpose of this study was to gain a better understanding of the perceived benefits and barriers of CAF to utilize a CRC. For the purpose of providing CRC administration with an opportunity to better cater to these groups. It is hoped that this current study can help coordinate efforts to increase the physical activity levels of the CAF because they currently are the least likely to utilize the campus exercise facilities while they are the most in need of the health benefits exercise brings.

As previously mentioned, one significant finding from this study was that AAF are not motivated to exercise by body image like many Caucasian women are. Much of the marketing to women about fitness in the American culture is constructed around the idea that they want to exercise to lose weight, become thin, and achieve and ideal body image (Tomlinson, 2011). This approach is not relevant to AAF women according to this research. Yet, as negative as the literature has portrayed AAF's level of physical activity, there is a program aimed at getting AAF more physically active. This program is titled, Black Women 'Do' Workout (BWDW) (Tomlinson, 2011). The program uses Facebook as a tool to encourage regular exercise participation among AAF. This program is based on information sharing, showing praise, encouragement, inspiration, and support in the way of sisterhood and by championing individuals for their fitness goals, which is hoped to keep others motivated to want to do the same. The BWDW program presents a 
best practice model for building supportive and effective health networks within communities of African descent.

Considering the top five barriers to physical activity as reported by this study, those were (1) "too tired" (2) "not enough time" (3) "too busy" (4) "lacked motivation" and (5) "work". These five barriers from this study are valid reasons that affect CAF being physical active. The literature suggests one-method CRC staffs can implement to improve physical activity among CAF, is a 'buddy system.' Tucker and Irwin (2006) investigated the usefulness of a buddy system for Canadian college students to being physically active. This study found the buddy system to be a positive method of having and getting college students to be physically active. For this study many of the participants buddied up with a friend or were matched up with another person from the study. The researchers alluded to the idea that the buddy system is a good way for college students to be physically active. The researchers also cautioned that the administration, set up and maintenance of the buddy system is a fact to be considered if implemented. Yet, this buddy system can be beneficial for college students. In this study a majority of the participants were female, thus these results from this study can be very applicable to this study.

University campus recreation staff and researchers should work together to address specific barriers to physical activity and improve the campus fitness center usage rates. They should further develop a more effective campus wide marketing campaign focusing on the health and long term fitness benefits of working out as opposed to the body image focus utilized by most of the current physical activity campaigns on college campuses. Another suggestion to improve campus fitness center usage was to develop a peer centered health education program with a workout partner system. It is also recommended that manager's hire and train a more diverse staff of fitness instructors with the hopes of making classes more approachable was voiced. Further, it is recommended to develop more programs, which would be attractive to AAF, along with dance fitness courses and culturally appropriate music.

Across many college campuses many diverse and minority populations do not have adequate access that encourage physical activity. From a young age, students do not develop proper exercise habits, which may lead to a lifetime of negative health consequences (D'Alonzo \& Fischetti, 2008). Colleges and universities can play a role in reducing negative health consequences by effectively marketing their campus recreation centers to a diverse student population. For many CAF, this is their last opportunity to have positive experiences with physical activity and access to a recreation center (Barney \& McGaha, 2006).

\section{Implications of this Study}

Findings in this study suggest that marketing the fitness and physical activity opportunities of the campus recreation center should not take a cookie cutter approach, rather managers and health educators should look at the diverse make up of their campus, determine the service and needs of the CAF population and market accordingly. Simple changes, such as female instructors, instructors of ethnic backgrounds, music that will be attractive to the CAF population. The messages regarding physical activity and the offerings of the campus recreation center can make a difference in participation rates and increase the health of the campus.

A major selling point on many of today's college campuses is the fitness facility. Many students take advantage of these facilities and the programs that are offered. Concurrent with previous literature, CAF rank among the lowest groups of participants at college facilities. Research has shown that CRC's have the opportunity to expose college students to positive experiences that will lead to being physically active throughout their life (Barney \& McGaha, 2006). Health educators must not only educate but also inspire all (gender and ethnicity) groups to take advantage of the services that are offered on their college campus.

\section{Study Limitations \& Future Research}

The researchers of this study noted a limitation for this study. One was the use of a sample of convenience. Participants were from one university and may not have been representative of other students at other universities.

When looking to further the research on this topic of improving physical activity of the CAF, looking at the effects of male and female instructors and their effects on CAF physical activity. Also, looking at instructors 
of different ethnic backgrounds. Another variable that can be investigated is the types of music CAF listen to while they exercise, and if it helps them maintain exercise regiment. These types of studies will continue the aid CRC administrators and health educators to benefit $\mathrm{CAF}$.

\section{References}

Ainsworth, B., Wilcox, S., Thompson, W., Richter, D., Henderson, K. (2003). Personal, social, and physical environmental correlates of physical activity in African-American women in South Carolina. American Journal of Preventive Medicine, 25(3Si), 23-29.

American College Health Association- Task Force on National Health Objectives (2010). Healthy Campus 2010: Making it Happen. Retrieved from: http:// www.acha.org/topics/hc2010.cf

American College of Sports Medicine. (2006). ACSM's guidelines for exercise testing and prescription $\left(7^{\text {th }}\right.$ ed.). Baltimore, MD: Lippincott Williams \& Wilkins.

Banks-Wallace, J., Conn, V. (2002). Interventions to promote physical activity among African American Women. Public Health Nursing, 19(5), 321-335.

Barney, D. \& McGaha, P. (2006). College students' perspectives and after course participation in basketball and tennis classes. Journal of International Council for Health, Physical Education, Recreation, Sport and Dance, XLII, (3), 23-26.

Barney, D., Miller, B.M., \& Kensinger, W.S. (2010). Recreation centers: If you build it, they might come. Poster session presented at the 2010 American Association of Physical Activity and Recreation/ American Alliance for Health, Physical Education, Recreation and Dance (AAPAR/AAHPERD) National Convention in Indianapolis, Indiana.

Barney, D., Pleban, F., Wilkinson, C., \& Prusak, K. (2015). Identifying high school physical education physical activity patterns after high school. The Physical Educator, 72, 278-293.
Behrens, T. \& Dinger, M. (2003). A preliminary investigation of college students' physical activity patterns. American Journal of Health Studies 18, 169-172.

Bouchard, C., \& Shephard, R.J. (1994). Physical activity fitness and health: The model and key concepts. In C. Boushard \& R.J. Shephard (Eds.), Physical activity, fitness, and health: International proceedings and consensus statement (Vol. 1, pp. 77-88). Champaign, IL: Human Kinetics.

Buckworth, J., \& Nigg, C. (2004). Physical activity, exercise and sedentary behavior in college students. Journal of American College Health 53(1), 28-34.

Conroy, M.B., Cook, N.R., Manson, J.E., Buring, J.E., \& Lee, I. (2005). Past PA, current PA, and risk of coronary heart disease. Medicine \& Science in Sports \& Exercise, 1251-1256.

D’Alonzo, K. \& Fischetti, N. (2008). Cultural beliefs and attitudes of black and hispanic college-age women toward exercise. Journal of Transcultural Nursing 19(2), 175-183.

DeVahl, J., King, R., \& Williamson, J. (2005). Academic incentives for students can increase participation in and effectiveness of a physical activity program. Journal of American College Health 53(6), 295-298.

Fountaine, C.J., Liguori, G.A., Mozumdar, A., \& Schuna, J.M. (2011). Physical activity and screen time sedentary behaviors in college students. International Journal of Exercise Science, 4, 102-112.

Haskell, W.L., Lee, I.M., Pate, R.R., Powell, K.E., Blair, S.N., Franklin, B.A., \& Bauman, A. (2007). Physical activity and public health: Updated recommendation for adults for the American college of sports medicine and the American heart association. Circulation, 116, 1081-1093.

Kahn, E.B., Ramsey, L.T., Brownson, R.C., et. al. (2002). The effectiveness of interventions to increase physical activity. A systematic review. American Journal of Preventive Medicine, 22(4s), 73-107. 
Mueller, A., \& Skamp, K. (2003). Teacher candidates talk: Listen to the steady beat of learning to teach. Journal of Teacher Education, 54, (5), 428-440.

Nies, M., Vollman, M., Cook, T. (1999). African American women's experiences with physical activity in their daily lives. Public Health Nursing, 16(1), 23-31.

Pate, R.R., Pratt, M., Blair, S.N., Haskell, W.L., Macera, C.A., Bouchard, C., Bushner, D., Ettinger, W., Heath, G.W., \& King, A.C. (1995). Physical activity and public health: A recommendation from the centers of disease control and prevention and the American college of sport medicine. The Journal of the American Medical Association, 273, 402-407.

Reed, J. \& Phillips, D. (2005) Relationships between physical activity and the proximity of exercise facilities and home exercise equipment used by undergraduate university students. Journal of American College Health, 53(6), 286-290.

SPSS (Student Version 21.0) [Software]. (2012). Thousand Oaks, CA: Sage Publications.
Steinhardt, M.A., \& Dishman, R.K. (2989). Reliability and validity of expected outcomes and barriers for habitual physical activity. Journal of Occupational Medicine, 31, (6), 536-546.

Strand, B.N., Egeberg, J., \& Mozumdar, A. (2010). The prevalence and characteristics of wellness programs and centers at two-year and four-year colleges and universities. Recreational Sports Journal, 34, 45-57.

Tomlinson, S. (2011). Black women "do workout!". The Sport Journal, 14, 1-3.

Tucker, P., \& Irwin, J.D. (2006). Feasibility of a campusbased "buddy system" to promote physical activity: Canadian students' perspectives. Journal of Physical Activity and Health, 3, (3), 323-334.

U.S. Department of Health and Human Services. (1996). Healthy people 2010: National health promotion and disease prevention objectives- PA and fitness. Washington, DC: US Government Printing Office.

Wexler, E. (March, 2016). No pain, No gain. American College Health Association. Retrieved from http:// www.acha.org.healtycampus 


\section{Table 1. Benefits and Barriers of Physical Activity Survey.}

Age:___ Year in School: Fr.___ Soph.__ Jr.__ Sr.__ Grad.

How big was the community where you spent the majority of your time growing up prior to attending the university?

_ $<500$ people

_ 501 to 3000 people

3001 to 10,000 people

_ 10,001 to 50,000 people

_ 50,001 to 200,000 people

_ 200,001 to $1,000,000$ people

_ $1,000,000$ people

What was the ethnic distribution of the students in your high school? If you attended more than on high school, think about the high school where you spent the most time. You should approximate a percentage for each group such that the total equals 100\%.

Caucasian

African American

_ Native American

_ Hispanic

__ Asian/Pacific Islander

_ Other

Did your high school have physical education (PE) classes?

Yes (please go to question 9)

No (please go to question 11)

Don't know/Don't remember

If you answered 'yes' to the previous question, was PE required?

_ Yes

- No

__ Don't know/Don't remember

On a scale of 1-10 (1=not at all meaningful, 10=very meaningful), how meaningful was PE? (please circle your response)

Not at all meaningful Extremely Meaningful

$\begin{array}{llllllllll}1 & 2 & 3 & 4 & 5 & 6 & 7 & 8 & 9 & 10\end{array}$

Not including any school sponsored physical education, were you physically active in high school?

_ Yes

No

Don't know/Don't remember

Think about some of the common barriers to regular physical activity. Identify how much you agree or disagree with each statement based on the following scale (1=strongly disagree, $5=$ strongly agree) by circling the response that matches your current attitude.

NOTE: For the purpose of this survey, physical activity and exercise are used interchangeably to mean any purposeful activity done to improve health and fitness. Walking to class would not be considered exercise, but yoga, lifting weights, running, working out on the elliptical trainer, swimming, etc. would constitute physical activity. 
It is difficult to be physically active because...

\begin{tabular}{|c|c|c|c|c|c|}
\hline & $\begin{array}{l}\text { Strongly } \\
\text { Disagree }\end{array}$ & Disagree & Neutral & Agree & $\begin{array}{l}\text { Strongly } \\
\text { Agree }\end{array}$ \\
\hline $\begin{array}{l}\text { I do not feel like } \\
\text { I Know how to be } \\
\text { Physically active. }\end{array}$ & 1 & 2 & 3 & 4 & 5 \\
\hline $\begin{array}{l}\text { I do not have enough } \\
\text { Free time. }\end{array}$ & 1 & 2 & 3 & 4 & 5 \\
\hline $\begin{array}{l}\text { I am not motivated to } \\
\text { Be physically active. }\end{array}$ & 1 & 2 & 3 & 4 & 5 \\
\hline $\begin{array}{l}\text { I do not have } \\
\text { Experience because } \\
\text { I Have never been } \\
\text { Physically active } \\
\text { Before. }\end{array}$ & 1 & 2 & 3 & 4 & 5 \\
\hline $\begin{array}{l}\text { I am not concerned } \\
\text { About gaining weight }\end{array}$ & 1 & 2 & 3 & 4 & 5 \\
\hline $\begin{array}{l}\text { I consider exercise } \\
\text { To be predominantly } \\
\text { "white behavior'. }\end{array}$ & 1 & 2 & 3 & 4 & 5 \\
\hline $\begin{array}{l}\text { I do not fully } \\
\text { Understand the health } \\
\text { Benefits of exercise. }\end{array}$ & 1 & 2 & 3 & 4 & 5 \\
\hline $\begin{array}{l}\text { I do not define } \\
\text { Overweight as being } \\
\text { Unhealthy. }\end{array}$ & 1 & 2 & 3 & 4 & 5 \\
\hline $\begin{array}{l}\text { I do not think } \\
\text { Exercise will help me } \\
\text { Achieve my body ideal }\end{array}$ & 1 & 2 & 3 & 4 & 5 \\
\hline $\begin{array}{l}\text { I do not believe } \\
\text { The CRC is set up } \\
\text { For beginners. }\end{array}$ & 1 & 2 & 3 & 4 & 5 \\
\hline $\begin{array}{l}\text { I think the CRC is } \\
\text { Too crowded. }\end{array}$ & 1 & 2 & 3 & 4 & 5 \\
\hline $\begin{array}{l}\text { My family and } \\
\text { Friends do not } \\
\text { Support my physical } \\
\text { Activity. }\end{array}$ & 1 & 2 & 3 & 4 & 5 \\
\hline
\end{tabular}




\begin{tabular}{|c|c|c|c|c|c|}
\hline & $\begin{array}{l}\text { Strongly } \\
\text { Disagree }\end{array}$ & Disagree & Neutral & Agree & $\begin{array}{l}\text { Strongly } \\
\text { Agree }\end{array}$ \\
\hline $\begin{array}{l}\text { I am afraid of being } \\
\text { Perceived as a } \\
\text { Tomboy. }\end{array}$ & 1 & 2 & 3 & 4 & 5 \\
\hline $\begin{array}{l}\text { I do not like the } \\
\text { Pressure to conform } \\
\text { To a specific } \\
\text { Standard of beauty. }\end{array}$ & 1 & 2 & 3 & 4 & 5 \\
\hline $\begin{array}{l}\text { I cannot find } \\
\text { Convenient locations } \\
\text { For exercise. }\end{array}$ & 1 & 2 & 3 & 4 & 5 \\
\hline $\begin{array}{l}\text { I don't like to } \\
\text { Exercise in front of } \\
\text { Other people. }\end{array}$ & 1 & 2 & 3 & 4 & 5 \\
\hline $\begin{array}{l}\text { I don't feel } \\
\text { Comfortable working } \\
\text { Out in front of men. }\end{array}$ & 1 & 2 & 3 & 4 & 5 \\
\hline $\begin{array}{l}\text { It is too time } \\
\text { Consuming to re-do my } \\
\text { Hair when I'm done. }\end{array}$ & 1 & 2 & 3 & 4 & 5 \\
\hline $\begin{array}{l}\text { I'm afraid of becoming } \\
\text { Too muscular. }\end{array}$ & 1 & 2 & 3 & 4 & 5 \\
\hline $\begin{array}{l}\text { It is difficult to get } \\
\text { Ready at the CRC. }\end{array}$ & 1 & 2 & 3 & 4 & 5 \\
\hline $\begin{array}{l}\text { I don't feel like } \\
\text { The current program } \\
\text { At the CRC are } \\
\text { Marketing to me. }\end{array}$ & 1 & 2 & 3 & 4 & 5 \\
\hline $\begin{array}{l}\text { The current programs } \\
\text { At the CRC are not } \\
\text { Interesting to me. }\end{array}$ & 1 & 2 & 3 & 4 & 5 \\
\hline \multicolumn{6}{|c|}{ Is being physically active important to you? } \\
\hline $\begin{array}{lll}\text { Not } & \text { at } & \text { all important } \\
1 & 2 & 3\end{array}$ & & 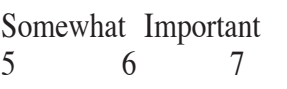 & 8 & $\begin{array}{l}\text { Extremely Important } \\
9 \quad 10\end{array}$ & \\
\hline
\end{tabular}


Table 2. Benefits to Physical Activity in AAF.

\begin{tabular}{ll}
\hline Item & Mean \\
\hline For good health & $4.45 \pm 1.02$ \\
To stay in shape & $4.33 \pm 0.96$ \\
To maintain proper body weight & $4.29 \pm 1.08$ \\
To make me feel better in general & $4.29 \pm 1.04$ \\
To reduce stress and relax & $4.16 \pm 1.04$ \\
To improve appearance & $4.08 \pm 0.97$ \\
To lose weight & $4.04 \pm 1.19$ \\
For a positive psychological effect & $4.00 \pm 0.97$ \\
For enhancing self-image and confidence & $4.00 \pm 1.17$ \\
For fun and enjoyment & $3.95 \pm 0.85$ \\
To help cope with life pressures & $3.75 \pm 1.18$ \\
For companionship & $2.83 \pm 1.16$ \\
\hline
\end{tabular}

Table 3. Benefits to Physical Activity.

\begin{tabular}{|c|c|c|c|}
\hline Item & Mean & & \\
\hline & Overall & Caucasian & African American \\
\hline For good health & $4.537 \pm 0.72$ & $4.544 \pm 0.69$ & $4.45 \pm 1.02$ \\
\hline To stay in shape & $4.537 \pm 0.70$ & $4.553 \pm 0.67$ & $4.33 \pm 0.96$ \\
\hline To maintain proper body weight & $4.440 \pm 0.77$ & $4.454 \pm 0.74$ & $4.29 \pm 1.08$ \\
\hline To make me feel better in general & $4.522 \pm 0.75$ & $4.541 \pm 0.72$ & $4.29 \pm 1.04$ \\
\hline To reduce stress and relax & $4.380 \pm 0.88$ & $4.400 \pm 0.86$ & $4.16 \pm 1.04$ \\
\hline To improve appearance* & $4.414 \pm 0.72$ & $4.442 \pm 0.68$ & $4.08 \pm 0.97$ \\
\hline To lose weight & $4.264 \pm 0.97$ & $4.281 \pm 0.95$ & $4.04 \pm 1.19$ \\
\hline For a positive psychological effect* & $4.350 \pm 0.83$ & $4.384 \pm 0.81$ & $4.00 \pm 0.97$ \\
\hline For enhancing self-image and confidence & $4.406 \pm 0.81$ & $4.446 \pm 0.76$ & $4.00 \pm 1.17$ \\
\hline For fun and enjoyment & $3.675 \pm 1.14$ & $3.636 \pm 1.16$ & $3.95 \pm 0.85$ \\
\hline To help cope with life pressures & $3.959 \pm 1.05$ & $3.975 \pm 1.04$ & $3.75 \pm 1.18$ \\
\hline For companionship & $3.003 \pm 1.18$ & $3.016 \pm 1.19$ & $2.83 \pm 1.16$ \\
\hline Subscale psychologic & $19.369 \pm 3.84$ & $19.413 \pm 3.83$ & $18.708 \pm 4.13$ \\
\hline Subscale body image* & $17.526 \pm 2.67$ & $17.624 \pm 3.83$ & $16.416 \pm 3.87$ \\
\hline Subscale health & $13.597 \pm 1.99$ & $13.636 \pm 1.88$ & $13.083 \pm 2.91$ \\
\hline
\end{tabular}


Table 4. Barriers to Physical Activity in AAF.

\begin{tabular}{ll}
\hline Item & Mean \\
\hline I'm too tired & $3.33 \pm 1.04$ \\
I don't have enough time & $3.33 \pm 1.30$ \\
I'm too busy & $3.33 \pm 1.30$ \\
Lack of motivation & $3.12 \pm 1.22$ \\
I'm too lazy & $2.58 \pm 1.05$ \\
It interferes with work & $2.41 \pm 1.34$ \\
I have nobody to workout with & $2.37 \pm 1.34$ \\
Because of bad weather & $2.37 \pm 1.31$ \\
It interferes with school & $2.37 \pm 1.01$ \\
I feel uncomfortable working out in front of others & $2.25 \pm 1.32$ \\
It's too inconvenient & $2.16 \pm 1.12$ \\
I don't know how to workout & $2.08 \pm 1.17$ \\
Because of family obligations & $2.08 \pm 1.21$ \\
Because exercise is too boring & $2.04 \pm 1.08$ \\
I get too fatigued by exercise & $1.91 \pm 1.05$ \\
There is a lack of facilities & $1.91 \pm 0.97$ \\
I am scared of injury & $1.87 \pm 1.03$ \\
There is a limiting health reason & $1.79 \pm 0.93$ \\
\end{tabular}

Table 5. Barriers to Physical Activity.

\begin{tabular}{|c|c|c|c|}
\hline Item & Mean & & \\
\hline & Overall & Caucasian & African-American \\
\hline I'm too tired & $3.629 \pm 1.12$ & $3.659 \pm 1.12$ & $3.33 \pm 1.04$ \\
\hline I don't have enough time & $3.730 \pm 1.21$ & $3.763 \pm 1.20$ & $3.33 \pm 1.30$ \\
\hline I'm too busy & $3.794 \pm 1.21$ & $3.834 \pm 1.20$ & $3.33 \pm 1.30$ \\
\hline Lack of motivation & $3.569 \pm 1.21$ & $3.610 \pm 1.21$ & $3.12 \pm 1.22$ \\
\hline I'm too lazy & $3.007 \pm 1.32$ & $3.049 \pm 1.33$ & $2.58 \pm 1.05$ \\
\hline It interferes with work & $2.767 \pm 1.28$ & $2.796 \pm 1.27$ & $2.41 \pm 1.34$ \\
\hline Because of bad weather & $2.764 \pm 1.25$ & $2.805 \pm 1.24$ & $2.37 \pm 1.31$ \\
\hline It interferes with school** & $3.153 \pm 1.26$ & $3.219 \pm 1.26$ & $2.37 \pm 1.01$ \\
\hline It's too inconvenient & $2.486 \pm 1.16$ & $2.514 \pm 1.16$ & $2.16 \pm 1.12$ \\
\hline Because of family obligations & $1.981 \pm 1.05$ & $1.975 \pm 1.04$ & $2.08 \pm 1.21$ \\
\hline Because exercise is too boring & $2.370 \pm 1.14$ & $2.414 \pm 1.14$ & $2.04 \pm 1.08$ \\
\hline I get too fatigued by exercise & $2.131 \pm 1.05$ & $2.161 \pm 1.05$ & $1.91 \pm 1.05$ \\
\hline There is a lack of facilities & $1.850 \pm 0.92$ & $1.846 \pm 0.92$ & $1.91 \pm 0.97$ \\
\hline There is a limiting health reason & $1.913 \pm 1.04$ & $1.929 \pm 1.05$ & $1.79 \pm 0.93$ \\
\hline Subscale Time* & $13.445 \pm 4.04$ & $13.614 \pm 4.06$ & $11.458 \pm 3.43$ \\
\hline Subscale Effort* & $17.194 \pm 5.12$ & $17.410 \pm 5.19$ & $15.166 \pm 3.90$ \\
\hline Subscale Obstacles & $8.059 \pm 2.91$ & $8.556 \pm 2.94$ & $8.166 \pm 2.74$ \\
\hline
\end{tabular}




\section{Appendix. Questions asked to College Adult Females during Focus Group Interviews.}

- Where did you grow-up?

- Size of community you grew-up in?

- What was the percentage of ethnic groups in your high school?

- Growing up were your parents physically active.

- Did you have high school physical education?

- Were they physically active growing up and in high school?

- What prompts that would help you feel more comfortable going to the Colvin Center?

- What would encourage you to go to the Colvin Center?

- List three barriers from going to the Colvin Center.

- What do you like about physical activity?

- What don't you like about the Colvin Center?

- Are your friends physically active?

- Do you know how to be physically active?

- Is being physically active important to you? Why or Why not?

- What cost are associated with it (be physically active).

- Is there a reason why you or your parents were not physically active?

- What were some of the variables that did or did not influence you physically activity? (ex. Crime facilities)

\section{Correspondence}

David Barney, Ed.D.

Associate Professor

Brigham Young University

249 G Smith Field House

Provo, Utah 84602

(801) 422-6477

(801) 422-0930 FAX

David_Barney@byu.edu

Weston Kensinger, PhD, CHES

Lecturer of Health Education

Penn State Harrisburg

School of Behavioral Sciences and Education

Health Education Program

W314 Olmsted

777 West Harrisburg Pike

Middletown, PA 17057-4898

Phone: (717) 948-6515

weston.kensinger@psu.edu
Bridget Miller, Ph.D.

Associate Professor

Oklahoma State University

427 Willard Hall

Stillwater, Oklahoma 74078

(405) 744-7680

Bridget.miller@okstate.edu

Scott Jordan, Ph.D.

Associate Professor

Northern Michigan University

1401 Presque Isle Ave.

Marquette, Michigan 49855-5301

scjordan@nmu.edu 